UDC 61

\title{
THE INITIAL STEPS OF A NON-SURGICAL INTERVENTION AND THE RESULTS ON CHILDREN IN ACEH, INDONESIA: A REPORT OF FOUR CASES
}

\author{
Dimiati Herlina \\ Division of Children Cardiology, Department of Children Health Science, Faculty of Medicine, \\ University of Syiah Kuala \& Dr Zainoel Abidin Regional Hospital, Banda Aceh, Indonesia \\ E-mail: herlinadimiati@yahoo.com
}

\begin{abstract}
Patent Ductus Arteriosus (PDA) is a condition of open Ductus Arteriosus after the baby is born. PDA connects the blood circulation of the aorta and the pulmonary artery, an increase in blood volume in the left heart which ends in heart failure in a child will happen. With the development of non-surgical intervention technology, this action can replace the surgical position in the management of a case so the morbidity rate of Congenital Heart Disease (CHD) can be suppressed. Several hospitals in Indonesia have routinely taken this action; Aceh has only just begun in 2017. Non-surgical intervention has been reported in four (4) children with PDA. Evaluation after one (1) year of action shows an increase in the child's weight or a change on the nutritional status towards normal. This action is very effective and gives satisfying results. After a financing agreement with the health guarantor (BPJS), this action becomes the first choice for the management of children with PDA at our hospital (Dr. Zainoel Abidin Hospital, Banda Aceh).
\end{abstract}

\section{KEY WORDS}

Patent Ductus Arteriosus, non-surgical intervention, improvement, nutritional status.

Indonesia, with a population of almost 265 million, is estimated to have 5 million babies every year. Estimated incidence of Congenital Heart Disease (CHD) is 8-10 per 1000 babies born alive, so there will be an additional 40,000 to 50,000 babies with CHD every year. Of this number, $50 \%$ need a surgery in childhood. At present, new cardiac surgery and nonsurgical interventions throughout Indonesia are carried out in no more than 1,500 cases per year-where are the others? Most may have died without having reached a sophisticated heart service center or a diagnosis of heart structure problems may not be found. Many babies die from CHD which can contribute to the high infant mortality rate in Indonesia (Harimurti, 2001).

At present, non-surgical interventions are advancing all over the world rapidly after Amplatzer devices are available. With this tool, doctors can close the hole in the heart. Several hospitals in Indonesia, such as Harapan Kita Heart Hospital (Jakarta), Dr. Cipto Mangunkusumo Hospital (Jakarta), Sardjito Hospital (Jogjakarta), Hasan Sadikin Hospital, Dr. Soetomo Hospital (Surabaya), Dr. Kariadi Hospital (Semarang), Sanglah Hospital (Bali), Adam Malik Hospital (Medan), and Abdul Muluk Hospital (Palembang), have routinely worked on non-surgical interventions (Rahajoe, 2007). This procedure has an advantage over surgery to name (1) it does not require long treatment in the intensive care unit, (2) it gives minimal bleeding, (3) it does not develop scarring on the chest wall, which has a positive impact on the aesthetic aspect, and (4) it shows a high success rate (Butera et al., 2004).

Dr. Zainoel Abidin Hospital is a regional hospital in the Province of Aceh which had only taken non-surgical interventions in $\mathbf{2 0 1 7}$ after the catheterization laboratory facilities and other support for this action were present. In that year, the closure of Ductus Arteriosus was carried out in four (4) children with an acyanotic type of CHD namely Patent Ductus Arteriosus (PDA).

Patent Ductus Arteriosus (PDA) is a ductus arteriosus that remains open after the baby is born; it is one type of CHD most often occurs in low birth weight babies or premature ones. The incidence ranges from 8 to $15 \%$ of all CHD, girls are twice as likely to suffer as boys 
(Krichenko et al., 1989; Rao, 2001). The ductus arteriosus connects the aorta to the left pulmonary artery so it can increase the volume load in the left heart. PDA with a large size of severe clinical symptoms occurs in the first week of the baby's age and can cause heart failure

The purpose of this paper is to report non-surgical interventions in four (4) children with PDA and evaluation of child development after one (1) year of action.

Case Illustration:

Case 1: A boy aged 1 year 10 months, weight $6.5 \mathrm{~kg}$, height $89 \mathrm{~cm}$ (a poor nutritional status), born premature weighing 2000 grams, routinely seeks treatment at the pediatric cardiac clinic at Dr. Zainoel Abidin after being diagnosed with Congenital Rubella Syndrome (KRS) at the age of 2 months. The heart problems are large PDA of $8.5 \mathrm{~mm}$ significant left to right shunt, ratio of Left Atrium (LA) and Aorta (Ao) is LA/Ao 1.9, congenital cataracts in both eyes, severe hearing loss. He has been treated for heart problems with furosemide, spironolactone, and enalapril. After being given an explanation of the child's illness and the actions that had to be taken so as not to cause heart failure in the future, the parents approve it. An explanation of the non-surgical interventions and the possibility that could occur during and after the procedure was given, followed by the signing of the procedure permit by both parents. An anesthetist carried out sedation. The treatment was done through the right vein and femoral arteries. The angiography showed a large PDA with an "A" shape on a size of 8-9 mm; there was no co-ratio of aorta and aorta regurgitation. The closure of PDA with the device from Lifetect (MFO) size 8/10 was done. After 15 minutes, an angiography evaluation is performed to reassess whether there were still PDA residuals, the device was released from the delivery sheet. The procedure lasted 28 minutes with 8 minutes 6 seconds flouro. There was no significant bleeding and the arterial pulses were good after 1 hour of the action. The next day, an evaluation on the position of the device was carried out by examining chest photos and echocardiography; the device was in a good position. At the age of two (2) years, a cataract surgery was performed at that time when the child's weight had risen to 9 kilograms in 2 months. At present the child is 2 years and 10 months with significant weight gain to 11.8 kilograms.

Case 2: A girl aged 5 years 7 months, weight $16.4 \mathrm{~kg}$, height $119 \mathrm{~cm}$ (a rather good nutritional status). She routinely seeks treatment at the pediatric cardiac clinic at Dr. Zainoel Abidin after being diagnosed with PDA at the age of two (2) years. On echocardiography, a large $10 \mathrm{~mm}$ PDA was seen, left atrium and left ventricle dilated, and LA/Ao ratio was 2.2. She always has recurrent lung infections. She was a full-term baby born with a birth weight of 2400 grams. A non-surgical intervention was performed under sedation by an anesthetist and an "A" PDA with a size of $10 \mathrm{~mm}$ was found. A PDA device from Lifetect (MFO) size 8/10 was used to close it. The action lasted for 30 minutes with 9 minutes flouro. After the action, there was no bleedin, and she showed good arterial pulses. Device position was good, reevaluation a day after the procedure showed no PDA residuals, and there was coarctation of the aorta and left pulmonary artery stenosis. In her last visit, there was a significant increase in body weight of 23.8 kilograms after 10 months of action (there was a weight gain of $7.4 \mathrm{~kg}$ )

Case 3: A girl aged 10 years 5 months, weight $20.6 \mathrm{~kg}$, height $109 \mathrm{~cm}$ (a poor nutritional status); she has been admitted five (5) times to the hospital with a diagnosis of pneumonia. She was a preterm baby (28-30 weeks) with birth weight of 2,200 grams. During the twentieth week of pregnancy, the mother experienced bleeding and she went through a cesarean section due to placenta previa. At the age of 1 year, the baby was diagnosed with a large PDA of $6 \mathrm{~mm}$, LA/Ao ratio of 1.7, but the parents refused to take PDA ligation surgery. The baby does not take treatment routinely. The closing of PDA using a PDA device from Lifetect (MFO) size 8/10 was done. On angiography, an "A" shaped PDA with a size of $8 \mathrm{~mm}$ was seen. The action lasted 56 minutes with flouro time of 10 minutes. There was no postprocedure bleeding, no PDA residuals, or coarctation of the aorta and PDA stenosis. She visited the cardiac clinic control 6 months later with a significant increase in body weight of $26.2 \mathrm{~kg}$ (an increase of $5.6 \mathrm{~kg}$ in 6 months). 


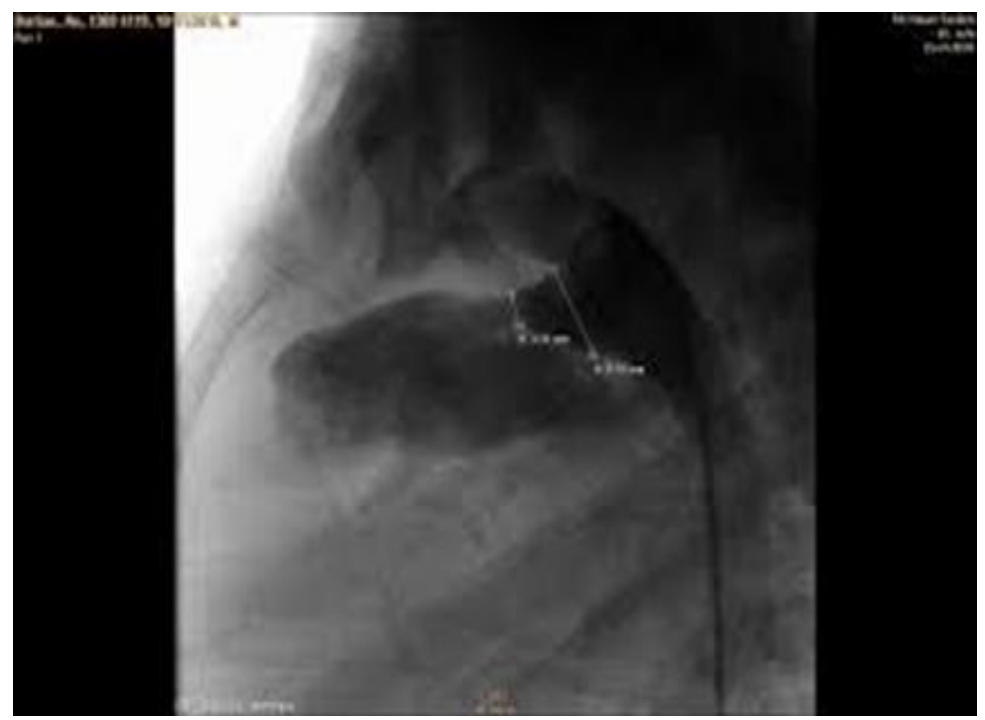

Figure 1 - The angiographic results of one of the patients on the size of the PDA

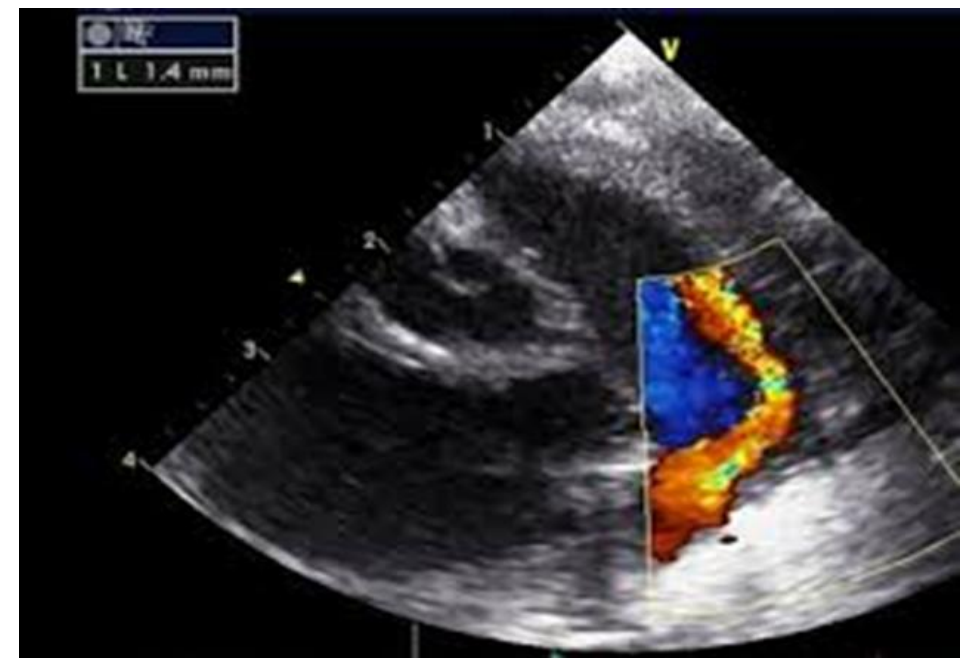

Figure 2 - The result of an echocardiography examination in one of the four children with a PDA. A $14 \mathrm{~mm}$ PDA is visible on the color Dopler check
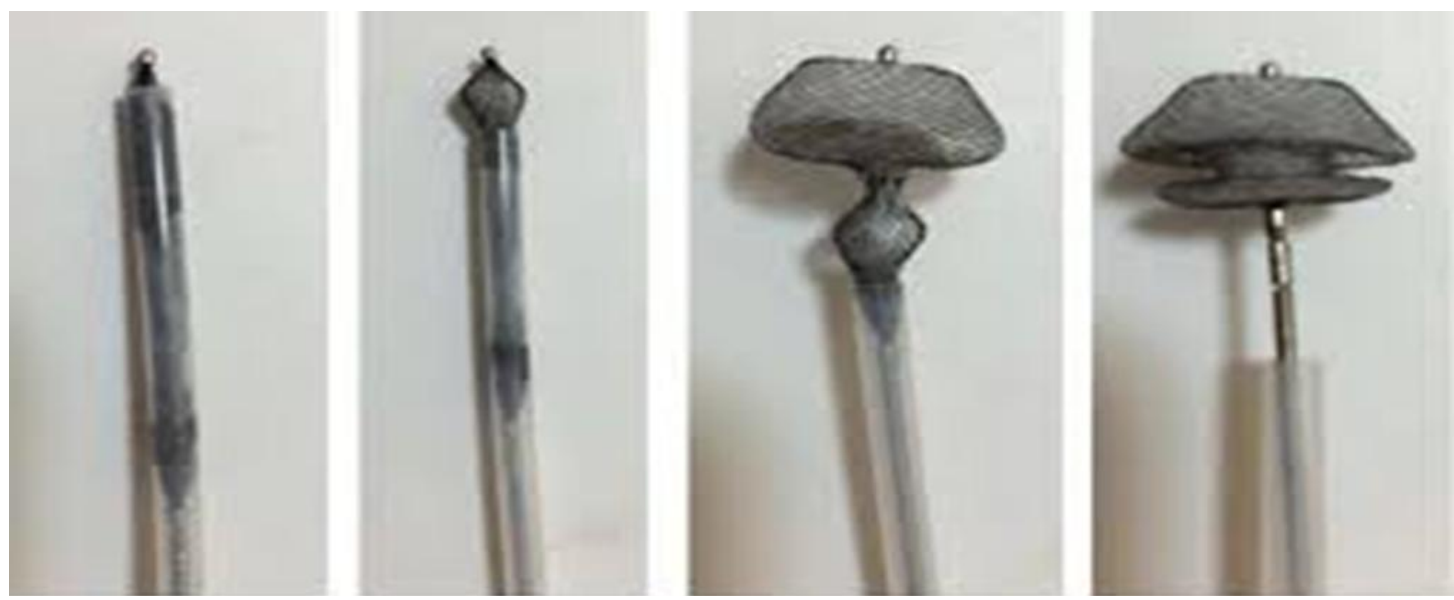

Figure 3 - PDA device installed in all the four children with no PDA residuals and left pulmonary artery stenosis on the echocardiographic evaluation series. On echocardiographic examination, the device is on the right position of the DA and does not block the flow of blood in the blood vessels to the lungs (left pulmonary artery) 
Case 4: A girl aged 4 years 9 months, weight $12.7 \mathrm{~kg}$, height $102 \mathrm{~cm}$ (a poor nutritional status), She routinely seeks cardiovascular treatment because PDA has been diagnosed for the first time at the age of 2 years, a $9 \mathrm{~mm}$ PDA with a ratio LA/Ao 2.4. She was a term baby with birth weight of 3,200 gr. The closure of PDA was carried out by sedation using a PDA device from Lifetect (MFO) size 8/10. On angiography, there was a large $10 \mathrm{~mm}$ PDA of an "A" shape. The action lasted 35 minutes with flouro 7 minutes 6 seconds. One year after the action, weight gain was $5.2 \mathrm{~kg}$ (currently her weight is $17.9 \mathrm{~kg}$ with a height of $108 \mathrm{~cm}$, with a rather good nutritional status).

Figure 1 shows the angiographic results of one of the patients on the size of the PDA.

In these four cases, the children came with growth problems, poor nutritional status, and significant hemodynamic changes (hs-PDA) due to the size of the PDA greater than 5 $\mathrm{mm}$ and the presence of left heart enlargement on echocardiography. This is in accordance with previous reports, stating that in children with PDA, there is left to right shunt, which results in excess blood to the lungs resulting in pulmonary hypertension; if the closure of the DA is not immediately performed, there is dilatation of the left atrium and left ventricular hypertrophy (left sided overload). This condition is known as ductal steal phenomenon (Benitz, 2016). Blood flow throughout the body decreases resulting in hypoperfusion to various organs and also to the muscles of the body. This is the cause for the children to suffer from malnutrition. In addition, the frequent occurrence of respiratory tract infections in children with PDA and pulmonary hypertension are other factors for the occurrence of disruption of child growth (Doyle, Kavanough-McGuch, \& Graham, n.d.; Hermes-Desantin \& Clyman, 2006). Other negative effects that cause growth disorders in a child with PDA is chronic hypoxia, which can cause malabsorption; this condition is also very important for the occurrence of cardiac cachexia (Leitch, 2000), but in these four cases the effects were not evaluated.

Diagnosis of hs-PDA can be established by echocardiography as a standard reference. In the four cases above, the echocardiographic criteria used is according to El Hajjar M. et al., that a minimum 2 of 3 criteria is found. In this case, the DA size is more than $1.4 \mathrm{~mm} / \mathrm{kg}$ body weight and the LA/Ao ratio is more than 1.4. This criterion has a sensitivity and specificity of more than $90 \%$ (Leitch, 2000).

In most cases of PDA, after getting an explanation from the doctor for the procedure that must be done for these children, more than $90 \%$ of parents refuse due to excessive fear, so the action is late and the disease continues with hemodynamic disorders and complications. With the development of the medical technology, a non-surgical alternative such as in these four cases with meaningful hemodynamic disorders can be done (Atiq, Aslam, \& Kazmi, 2007; Butera et al., 2004; Moore, Levi, Moore, Schneider, \& Berdjis, 2005). This action has advantages compared to surgical procedures, namely short treatment time, reduced risk of anesthesia, and no scar on tissues, especially in girls (Butera et al., 2004; Moore et al., 2005). Of these 4 cases, 3 were girls with a history of low birth weight $(75 \%)$. The incidence of PDA is twice as common in girls than boys, often occurring in premature and low birth weight (Butera et al., 2004; Rao, 2001). However, this action can also be at risk of embolization and hemolysis and protrusion of the device (Moore et al., 2005). In all the four cases, this condition does not occur. There are already many devices for PDA closure, in this case the device used is from Lifetect (PDA MPO or Multipurpose Occluder Device) because it is much cheaper compared to Amplatzer ductal occlude. Time of treatment does not last longer than 1 hour.

Results of evaluation in 3 months, 6 months, and 1 year post-action in the four cases showed a significant increase in body weight. This indicator shows that the child's heart performance is good because there is no left to right shunt (Atiq et al., 2007).

In case 1 (case of KRS), the congenital cataract surgery was performed on both eye lenses. The cataract surgery had been delayed because the heart had not been treated; the anesthetic consideration in a cataract surgery is included in the high ASA criterion, so the procedure for the eye is decided after the heart problem was resolved. Currently, the child is waiting for cochlear implant installation to solve the hearing problem. This is one case of many cases due to Rubella virus infection in the mother during the first trimester of 
pregnancy. Based on this case, we can educate other parents about the importance of the current MR immunization where the cases of KRS in Aceh have started to increase.

\section{CONCLUSION}

Four cases of children with PDA have been reported with successful performance of non-surgical interventions for PDA placement. There are no PDA residuals or other complications after the procedure. Evaluation after 1 year of the procedure show that the children's weight increased significantly with normal nutritional status according to their age. Although only 1 child shows KRS, the recommendation is related to the importance of the MR immunization campaign in Aceh.

\section{CONFLICT OF INTEREST}

There is no conflict of interest in this report.

\section{REFERENCES}

1. Atiq, M., Aslam, N., \& Kazmi, K. (2007). Transcatheter closure of small-to-large patent ductus arteriosus with different devices: Queries and challenges. J Invasive Cardiol, 19, 295-298.

2. Benitz, W. (2016). Committee on Fetus and Newborn Patent Ductus Arteriosus in Preterm Infants. Pediatrics, 137(1).

3. Butera, G., Rosa, G. De, Chessa, M., Piazza, L., Delogu, A., Frigiola, A., \& Carminati, M. (2004). Transcatheter closure of persistent ductus arteriosus with the Amplatzer duct occluder in very young symptomatic children. Heart, 90(12), 1467-1470.

4. Doyle, T., Kavanough-McGuch, A., \& Graham, T. (n.d.). Clinical and manifestations and diagnosis of patent ductus arteriosus. Retrieved August 24, 2018, from http://www.uptodate.com/contents/clinical-manifestations-and-diagnosis-of-patent-ductusarteriosus

5. Harimurti, G. M. (2001). Congenital Heart Disease in newborn infant in several Hospital in Indonesia, Presented in: Asean Congress of Cardiology 1997.

6. Hermes-Desantin, E., \& Clyman, R. (2006). Patent ductus arteriosus: pathophysiology and management. Perinatologi, 26, 14-18.

7. Krichenko, A., Benson, L., Burrows, P., Möes, C., McLaughlin, P., \& Freedom, R. (1989). Angiographic classification of the isdolated persistently patent ductus arteriosus and implications for percutaneous catheter occlusion. Am J Cardiol, 63, 877-880.

8. Leitch, C. (2000). Growth, nutrition and energy expenditure in pediatric heart failure. Prog Pediatr Cardiol, 11(3), 195-202.

9. Moore, J., Levi, D., Moore, S., Schneider, D., \& Berdjis, F. (2005). Interventional treatment of patent ductus arteriosus in 2004. Catheter Cardiovasc Interv, 64, 91-101.

10. Rahajoe, A. (2007). Layanan Jantung Anak di Indonesia. J. Kardiologi Indonesia, 6-9.

11. Rao, P. (2001). Coil Occlusion of the Large Patent Ductus Arteriosus. Journal Invasive Cardiology, 13(1), 36-38. 